University of Nebraska - Lincoln

DigitalCommons@University of Nebraska - Lincoln

Biochemistry -- Faculty Publications

Biochemistry, Department of

$6-1-2000$

\title{
Insect cellular reactions to the lipopolysaccharide component of the bacterium Serratia marcescens are mediated by eicosanoids
}

Jon C. Bedick

University of Nebraska-Lincoln, jbedick@shawnee.edu

R L. Pardy

rpardy2@unl.edu

R. W. Howard

USDA/ARS

David W. Stanley

University of Nebraska - Lincoln

Follow this and additional works at: https://digitalcommons.unl.edu/biochemfacpub

Part of the Biochemistry, Biophysics, and Structural Biology Commons

Bedick, Jon C.; Pardy, R L.; Howard, R. W.; and Stanley, David W., "Insect cellular reactions to the lipopolysaccharide component of the bacterium Serratia marcescens are mediated by eicosanoids" (2000). Biochemistry -- Faculty Publications. 19.

https://digitalcommons.unl.edu/biochemfacpub/19

This Article is brought to you for free and open access by the Biochemistry, Department of at DigitalCommons@University of Nebraska - Lincoln. It has been accepted for inclusion in Biochemistry -- Faculty Publications by an authorized administrator of DigitalCommons@University of Nebraska - Lincoln. 


\title{
Insect cellular reactions to the lipopolysaccharide component of the bacterium Serratia marcescens are mediated by eicosanoids
}

\author{
Jon C. Bedick ${ }^{a}$, R.L. Pardy ${ }^{\mathrm{b}}$, R.W. Howard ${ }^{\mathrm{c}}$, David W. Stanley ${ }^{\mathrm{a}, *}$ \\ a Insect Biochemical Physiology Laboratory, University of Nebraska - Lincoln, Lincoln, NE 68583-0816, USA \\ ${ }^{\mathrm{b}}$ Laboratory for the Biology of Lipopolysaccharides, University of Nebraska, Lincoln, NE 68588-0118, USA \\ ' USDA/ARS, 1515 College Avenue, Manhattan, KS 66502, USA
}

Received 28 January 2000; accepted 3 April 2000

\begin{abstract}
Nodulation, which begins with the formation of cellular microaggregates, is the predominant cellular defense reaction to bacterial infections in insects. We suggested that these reactions to bacterial infections are mediated by eicosanoids. The lipopolysaccharide (LPS) component of some bacterial cells stimulates defense reactions in mammals and insects. Here, we report on experiments designed to test the hypothesis that eicosanoids mediate microaggregation reactions to LPS. Injections of LPS (purified from the bacterium, Serratia marcescens) into larvae of the tenebrionid beetle, Zophobas atratus, stimulated microaggregation reactions in a dose-dependent manner. Treatments with eicosanoid-biosynthesis inhibitors immediately prior to LPS challenge sharply reduced the microaggregation responses. Separate treatments with specific inhibitors of phospholipase $\mathrm{A}_{2}$, cyclooxygenase and lipoxygenase reduced microaggregation, supporting our view that microaggregate formation involves lipoxygenase and cyclooxygenase products. The inhibitory influence of dexamethasone was apparent within $30 \mathrm{~min}$ after injection, and microaggregation was significantly reduced, relative to control insects, over the following $90 \mathrm{~min}$. The dexamethasone effects were reversed by treating LPS-injected insects with the eicosanoid precursor, arachidonic acid. These findings indicate that cellular defense reactions to a specific component of bacterial cells are mediated by eicosanoids, and open up new possibilities for dissecting detailed hemocytic actions in insect immune reactions to bacterial infections. (C) 2000 Elsevier Science Ltd. All rights reserved.
\end{abstract}

Keywords: Insect immunity; Eicosanoids; Lipopolysaccharide; Zophobas atratus

\section{Introduction}

Eicosanoid is a general term for all biologically active, oxygenated metabolites of three $\mathrm{C} 20$ polyunsaturated fatty acids, namely 20:3n-6, 20:4n-6 and 20:5n-3. Three main groups of eicosanoids are recognized (Stanley, 2000): (1) the prostaglandins and thromboxanes are products of the cyclooxygenase pathways; (2) epoxyeicosatrienoic acids are products of the so-called epoxygenase pathways; and (3) the lipoxygenase pathways are responsible for a large assemblage of products, including hydroxyeicosatetraenoic acids. These molecules serve as lipid mediators, which exert profound influences on cellular events in mammals. Indeed, eicos-

* Corresponding author. Tel.: +1-402-472-8710; fax: +1-402-4724687.

E-mail address: dstanley1@unl.edu (D.W. Stanley). anoids are appreciated best in the contexts of their clinical importance in human and animal medicine.

In addition to their medical importance, recognition of the biological significance of eicosanoids in invertebrates is rapidly growing (Stanley and Howard, 1998; Stanley, 2000). Some eicosanoid actions in invertebrates seem to be limited to a relatively small number of species. For example, prostaglandins release egg-laying behavior in only a few species of insects (StanleySamuelson and Loher, 1986). Alternatively, it appears that other eicosanoid actions are quite basic to animal physiology, and these actions occur in most, if not all animals. This may be so for certain events in reproduction, in modulation of ion-transport phenomena and in cell-mediated host defense reactions (Stanley, 2000).

We have been considering the idea that eicosanoids mediate cellular defense reactions to bacterial infections in insects, and perhaps all invertebrates, that undertake cellular host defense actions. We first found that tobacco 
hornworms, Manduca sexta, that had been treated with eicosanoid-biosynthesis inhibitors prior to experimental infections were unable to clear bacterial infections from hemolymph circulation (Stanley-Samuelson et al., 1991). Microaggregation and nodulation are early cellular actions responsible for clearing large numbers of bacterial cells from circulation (Horohov and Dunn, 1983). In our second line of work, we found that these two cellular actions were sharply impaired in tobacco hornworms that had been treated with eicosanoidbiosynthesis inhibitors prior to experimental infections (Miller et al., 1994). Subsequent studies revealed that eicosanoids mediate microaggregation and nodulation reactions to bacterial infections in other insect species, including the larvae of the beetle Zophobas atratus (Miller et al., 1996), true army worms, Pseudaletia unipuncta, black cutworms, Agrotis ipsilon (Jurenka et al., 1997), and silk moths, Bombyx mori (StanleySamuelson et al., 1997), all holometabolous insects. We also suggested that eicosanoids mediate cellular defense reactions to bacterial infections in adults of three hemimetabolous species, the cricket Gryllus assimilis (Miller et al., 1999) and the periodical cicadas, Magicicada septendecim and Magicicada cassini (Tunaz et al., 1999).

Eicosanoids mediate other aspects of insect immunity. Downer and colleagues suggested that eicosanoids mediate phagocytosis, cell spreading and the prophenyloxidase reactions to bacterial infections in larvae of the greater wax moth, Galleria mellonella (Mandato et al., 1997). Beyond these cellular reactions to infection, Morishima et al. (1997) found that eicosanoids mediate induction of two immune genes in the silkworm fat body, those for cecropin and lysozyme. Taken together, these results support our hypothesis that eicosanoids are important elements in the signal transduction processes that operate between a bacterial infection and the appearance of insect defense reactions.

We reported on the differential influence of four bacterial species on nodulation intensity for larvae of two insect species, M. sexta and Z. atratus (Howard et al., 1998). In both insects, we found that infections of two bacterial species, Serratia marcescens and Escherichia coli, resulted in high levels of nodulation, while identical infections with two other bacterial species, Bacillus subtilis and Sarcina flava, resulted in relatively low levels of nodulation. We inferred from these findings that insects are able to gage certain features of invading bacterial cells.

Outer features of bacterial cells, including peptidoglycan fragments and lipopolysaccharide, are involved in defense reactions to bacterial infections in vertebrates and invertebrates, and they are probably responsible for the differential nodulation reactions we observed. Peptidoglycan fragments induce synthesis of lysozyme in tobacco hornworms (Kanost et al., 1988). Similarly, LPS stimulates cellular aggregation and protein secretion
(Charalambidis et al., 1995). On the basis of our earlier work, we hypothesized that eicosanoids mediate insect cellular reactions to LPS. In this paper we report the results of experiments designed to test this idea. Working with larvae of the tenebrionid beetle, Z. atratus, we found that injections of purified LPS resulted in the formation of microaggregations, a phase in nodulation. The microaggregation reactions were attenuated by pretreating the hornworms with eicosanoid-biosynthesis inhibitors.

\section{Materials and methods}

\subsection{Insects}

Late-stage larvae of the beetle Z. atratus were purchased from Nature's Way (Ross, $\mathrm{OH}$ ) and maintained on a laboratory bench in terraria containing brewer's yeast, wheat flour and oatmeal, in a ratio of 1:16:128 (dry $\mathrm{v} / \mathrm{v}$ ). Water was provided by keeping damp towels on top of the mixture.

\subsection{Preparing LPS from S. marcescens}

There are several published protocols for preparing LPS, all of which yield LPS of differing purity. Here we describe an unpublished protocol used to yield pure LPS. S. marcescens (a wild-type strain provided by Dr Kenneth Nickerson, University of Nebraska, Lincoln) was grown to early stationary phase in Luria broth at the University of Nebraska fermentation facility. Cells were harvested by centrifugation and washed twice with deionized water and lyophilized. The dried cells constituted the starting material for the LPS extraction and purification.

Extraction and purification of LPS from S. marcescens involves four steps: delipidation, enzyme treatment, extraction of LPS and precipitation of LPS aggregates and, finally, ultracentrifugation.

\subsubsection{Delipidation}

Lyophilized cells were suspended at a ratio of $60 \mathrm{ml}$ solvent per gram of lyophilized cells and extracted sequentially with continuous stirring with each of the following solvents: $95 \%$ ethanol $(2 \mathrm{~h})$; absolute acetone $(2 \mathrm{~h})$; and diethylether $(1 \mathrm{~h})$. Cells were centrifuged from each solvent prior to the addition of the next solvent in the series. Following extraction with diethylether the cells were allowed to dry in air overnight in a chemical hood.

\subsubsection{Enzyme treatment}

Dried, delipidated cells were suspended in deionized water at a ratio of $20 \mathrm{ml}$ water per gram of initial lyophilized cells. DNAase and RNAase (Boehringer 
Mannheim) were added to the solution at $1 \mathrm{mg}$ each per $20 \mathrm{ml}$ water, and then the solution was brought to $4 \mathrm{mM}$ sodium azide. The mixture was incubated for $48 \mathrm{~h}$ at room temperature, after which $1 \mathrm{mg}$ of protease $\mathrm{K}$ per $20 \mathrm{ml}$ water was added and incubation continued at room temperature for $24 \mathrm{~h}$. The entire suspension was added to a pre-wetted dialysis bag (Spectra/Por, MWCO:6-8000). The suspension was dialyzed at room temperature in 41 of deionized water with stirring for $24 \mathrm{~h}$. The water was changed five times in this period. Following dialysis the cell suspension was centrifuged for $1 \mathrm{~h}$ at $5000 \mathrm{~g}$. The resulting cell pellet/sediment was washed two times with absolute acetone and dried overnight.

\subsubsection{LPS extraction and precipitation of LPS aggregates}

The cells were suspended in phenol $(10 \mathrm{ml}$ of $90 \%$ phenol per gram of lyophilized cells measured at the stage of starting material). This mixture was stirred continuously at $50^{\circ} \mathrm{C}$ in an oil bath. After $24 \mathrm{~h}$ the mixture was cooled to room temperature, chloroform $(10 \mathrm{ml}$ per gram of lyophilized cells) and petroleum ether $(16 \mathrm{ml}$ per gram of lyophilized cells) were added to the phenolcell suspension and stirring continued. After $30 \mathrm{~min}$ the mixture was centrifuged and the supernatant layer reserved. The sediment was re-extracted with $90 \%$ $\mathrm{phenol} / \mathrm{chloroform} /$ petroleum ether with stirring at room temperature. After $30 \mathrm{~min}$ the mixture was centrifuged. The combined supernatant layers were vacuum-evaporated in a rotary distillation apparatus (Buchi) at $50^{\circ} \mathrm{C}$ to remove all solvents (including water) so that the phenol solidified at room temperature. LPS aggregates were precipitated from the phenol by warming and adding sufficient deionized water to bring the total suspension to $85 \%$ phenol $(\mathrm{v} / \mathrm{v})$. The aggregates were sedimented from the phenol solution by centrifugation $(5000 \mathrm{~g}, 1 \mathrm{~h})$. The pelleted LPS was washed twice with $85 \%$ phenol and three times with absolute acetone. The final pellet was suspended in sufficient deionized water with sonication to form a particle-free, opalescent suspension. The $\mathrm{pH}$ of this suspension was adjusted to slightly more than $\mathrm{pH} 7$ using a few $\mu \mathrm{l}$ of $0.0075 \mathrm{M}$ triethanolamine and $\mathrm{pH}$ test strips. The suspension was dialyzed (same membrane as above) overnight at $4^{\circ} \mathrm{C}$ against several changes of deionized water. The resulting dialysate was finally lyophilized.

\subsubsection{Ultracentrifugation}

The dialyzed, lyophilized LPS was resuspended as above and ultracentrifuged at $77,000 \mathrm{~g}$ for $24 \mathrm{~h}$ at $4^{\circ} \mathrm{C}$. The resulting pellet was resuspended in deionized water and lyophilized. The dried, highly purified LPS was stored at $4^{\circ} \mathrm{C}$ until used. Purity was confirmed by analyzing the LPS on polyacrylamide gel electrophoresis, according to the methods of Bell and Bell (1988).

The LPS was prepared for larval injections by adding aliquots of pyrogen-free water to dried LPS. LPS forms micelles of varying sizes in water; stable suspensions were formed by sonicating samples for approximately $10 \mathrm{~min}$ at $40 \mathrm{~W}$ with a probe sonicator (VibraCell, Danbury, CT) to produce micelles.

\subsection{Injections and manipulations}

Test larvae were injected with either the $\mathrm{PLA}_{2}$ inhibitor dexamethasone [(11 $\beta, 16 \alpha)$-9-fluoro-11,17,21-trihydroxy-16-methylpregna-1,4-dione], the cyclooxygenase inhibitor ibuprofen [ $\alpha$-methyl-4-(2methylpropyl)benzeneacetic acid], or the lipoxygenase inhibitor esculetin (6,7-dihydroxycoumarin), all purchased from BioMol (Plymouth Meeting, PA). In some experiments, larvae were injected with arachidonic acid (5,8,11,14-eicosatetraenoic acid). Control larvae were injected with the drug vehicle, $95 \%$ ethanol. All injections of pharmaceuticals, except esculetin, were in a standard volume of $2 \mu \mathrm{l}$. Esculetin was injected in a volume of $10 \mu \mathrm{l}$. Except in dose-response experiments, the pharmaceutical products were injected in dosages of $26 \mu \mathrm{g} / \mathrm{larva}$ and arachidonic acid (20:4n-6) was injected at $20 \mu \mathrm{g} / \mathrm{larva}$.

\subsection{General procedures}

General procedures described in detail by Miller and Stanley (1998) are given here, and individual experiments are described in context in the Results section. Larvae were surface sterilized by swabbing with $95 \%$ ethanol. The insects were pretreated with a pharmaceutical product or control injection, then challenged with a standard dosage of $200 \mu \mathrm{g}$ of purified LPS. The injections were done using a 26 gage, 0.5 in needle attached to a $50 \mu \mathrm{l}$ syringe (Hamilton, Reno, NV). Microaggregation was assessed by applying $20 \mu \mathrm{l}$ of hemolymph on to a Brightline hemacytometer (AO Instrument, Buffalo, NY). The number of cellular aggregates (operationally defined as a cluster of nine or more cells) in each sample was estimated by direct counting, using the grid system, under phase contrast optics.

\subsection{Dose response for LPS}

Individuals in five groups of larvae were separately injected with $0,10,50,100$ or $200 \mu \mathrm{g}$ of LPS. After $1 \mathrm{~h}$ incubations, hemolymph was withdrawn and the number of cellular aggregates in each sample was estimated by direct counting as described above.

\subsection{Time course of nodulation: influence of dexamethasone}

Individuals in three groups of larvae were injected with $2 \mu \mathrm{l}$ of ethanol or with $26 \mu \mathrm{g}$ of dexamethasone in 
$2 \mu \mathrm{l}$ of ethanol. A control group was injected with the drug vehicle, $2 \mu \mathrm{l}$ ethanol, and then with $200 \mu \mathrm{g}$ LPS. An experimental group was injected with dexamethasone, and then with $200 \mu \mathrm{g}$ LPS. A third control group was included to assess the possible influence of the LPS vehicle, pyrogen-free water, on microaggreagation. This group was injected with $2 \mu \mathrm{l}$ ethanol, and then with $20 \mu \mathrm{l}$ water. The larvae were immediately injected with LPS as described. At 6, 12, 18, 30, 60, 90 and 120 min post-injection (PI), sub-groups of control and experimental insects were processed for assessing microaggregation as just described.

\subsection{Dose-response curves for dexamethasone}

Individuals in four groups of larvae were injected with $2 \mu \mathrm{l}$ of ethanol, or $0.26,2.6$ or $26 \mu \mathrm{g}$ of dexamethasone in $2 \mu \mathrm{l}$ ethanol, and then challenged with a standard dosage of LPS. At $1 \mathrm{~h} \mathrm{PI}$, the larvae were processed for assessing microaggregation as just described.

\subsection{Fatty acid rescue experiment}

Individuals in two groups of larvae were injected with either $2 \mu \mathrm{l}$ ethanol or $26 \mu \mathrm{g}$ of dexamethasone in $2 \mu \mathrm{l}$ of ethanol and challenged with LPS. Immediately after challenge, the dexamethasone-treated larvae were divided into two sub-groups. Individuals in one sub-group were treated with $20 \mu \mathrm{g}$ arachidonic acid in $2 \mu \mathrm{l}$ of ethanol. Another sub-group was treated with $2 \mu \mathrm{l}$ of ethanol to control for the effects of the extra injection on nodulation. At $1 \mathrm{~h} \mathrm{PI}$, the larvae were processed for assessing microaggregation as just described.

\subsection{Influence of other eicosanoid-biosynthesis inhibitors on nodulation}

We divided larvae into groups and injected individuals in each group with either ibuprofen or the lipoxygenase inhibitor esculetin, all in standard dosages of $26 \mu \mathrm{g}$ in $2 \mu \mathrm{l}$ of ethanol. Control insects were injected with $10 \mu \mathrm{l}$ of ethanol. Following injections, the larvae were challenged with LPS. At $1 \mathrm{~h} \mathrm{PI}$, the larvae were processed for assessing microaggregation.

\subsection{Statistical analysis}

Data on microaggregation were analyzed by analysis of variance (ANOVA) and significance was determined at $P<0.05$ using the Least Significant Difference (LSD) test.

\section{Results}

The beetle larvae formed hemocyte microaggregates in reaction to LPS injections by $1 \mathrm{~h}$ post-injection. The number of microaggregates increased in a linear way from about $0.4 \times 10^{5} / \mathrm{ml}$ in reaction to $5 \mu \mathrm{g}$ of LPS/larva to about $0.8 \times 10^{5} / \mathrm{ml}$ in reaction to $100 \mu \mathrm{g} /$ larva (Fig. 1). In this experiment, larger LPS dosages did not result in more microaggregates. With a view to maximizing microaggregation reactions in positive control experiments, we used $200 \mu \mathrm{g}$ LPS treatments in subsequent experiments.

We investigated the influence of incubation time on the formation of hemocyte microaggregates in reaction to $200 \mu \mathrm{g}$ LPS treatments (Fig. 2). The data represented by open circles show the normal time course of microaggregate formation in larvae challenged with LPS, then injected with ethanol to control for a second injection. We recorded negligible microaggregation at $6 \mathrm{~min} \mathrm{PI}$, which increased to about $0.3 \times 10^{5}$ at $12 \mathrm{~min}$ and then to nearly $1.5 \times 10^{5}$ microaggregates $/ \mathrm{ml}$ hemolymph by 18 min PI. Longer incubations did not result in significantly greater numbers of microaggregates. The data represented by the solid circles show the influence of the eicosanoid-biosynthesis inhibitor, dexamethasone, on numbers of microaggregates in reaction to $200 \mathrm{mg}$ LPS challenges. We recorded negligible numbers of microaggregates at $6 \mathrm{~min}$ PI, which increased to about $0.5 \times 10^{5}$ by $18 \mathrm{~min}$ PI; again, the numbers of microaggregates did not increase significantly with longer incubation periods. The third experiment (represented by solid triangles) was designed to control for the possibility that the handling and injecting procedures independently stimulate the microaggregate formation reaction. Fig. 2 shows that microaggregation reactions to injections of ethanol followed by pyrogen-free water yielded very low levels of microaggregate formation, which were not significantly

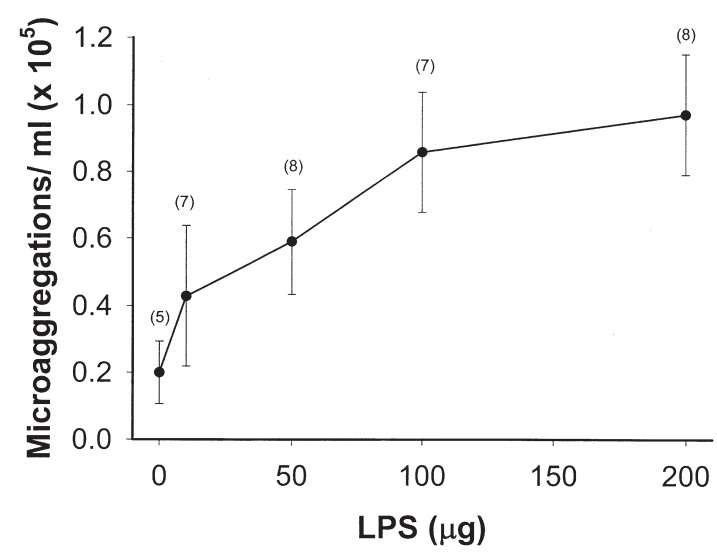

Fig. 1. The influence of LPS dosages, purified from the pathogenic bacterium $S$. marcescens, on numbers of microaggregates in the hemolymph from larvae of the beetle $Z$. atratus. The insects were injected with the amounts of LPS indicated, and after $1 \mathrm{~h}$ hemolymph samples were withdrawn and applied to a hemacytometer. Numbers of microaggregates were determined by direct counting. Data points represent mean numbers of microaggregates, and error bars indicate one standard error of the mean (SEM). Numbers in parenthesis indicate the number of individual insects in each experiment. 


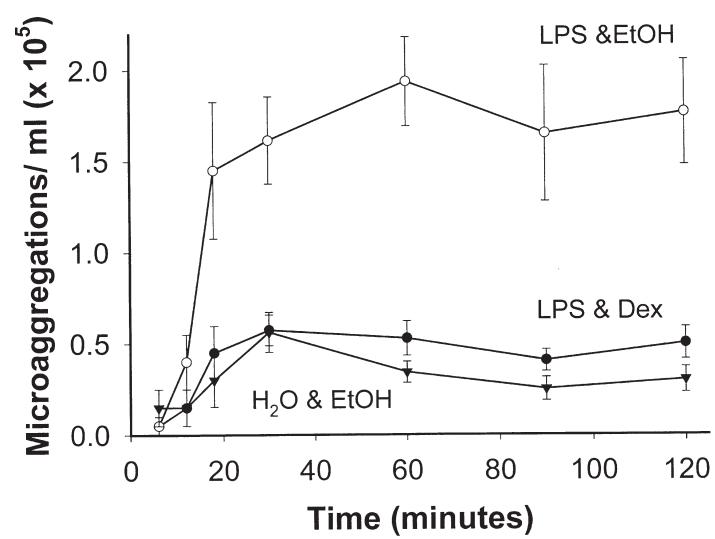

Fig. 2. Time course of microaggregation in larval beetles, Z. atratus, in response to injections of LPS $(200 \mu \mathrm{g})$. Test insects were first injected with dexamethasone (Dex; solid circle), and control insects were first injected with ethanol (EtOH; open circles). Within 3-10 min, both groups of insects were then intrahemocoelically injected with $200 \mu \mathrm{g}$ of LPS. An additional set of control insects (solid triangles) was treated with pyrogen-free water $\left(\mathrm{H}_{2} \mathrm{O}\right)$ and with ethanol. At the indicated times PI, microaggregation was assessed. Each point indicates the mean number of microaggregates found in each insect, and the error bars represent one SEM. Each point represents the mean of five or more separate experiments.

different from the results with dexamethasone treatments.

Fig. 3 shows that the influence of dexamethasone on microaggregate formation was expressed in a dosedependent way. Numbers of microaggregates declined from about $1.5 \times 10^{5}$ microaggregates $/ \mathrm{ml}$ hemolymph in insects treated with the drug vehicle, ethanol, and then injected with LPS, to about $0.5 \times 10^{5}$ microaggregates $/ \mathrm{ml}$ hemolymph in insects treated with the highest dosage.

The influence of dexamethasone on LPS-induced microaggregate formation was reversed by treating experimental insects with the eicosanoid precursor

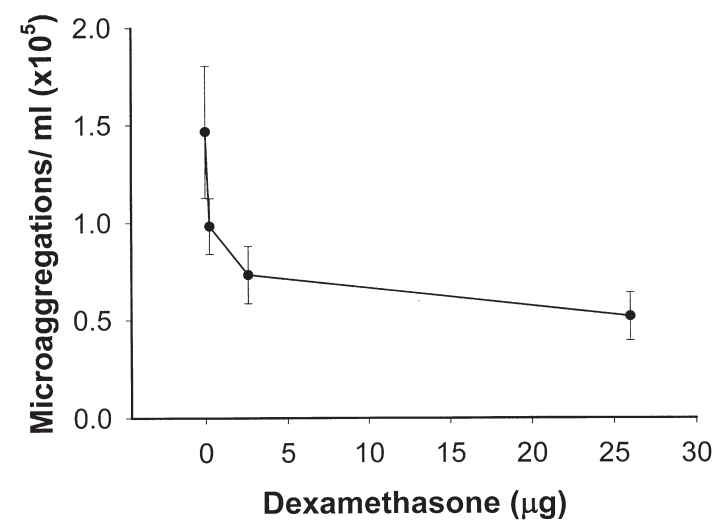

Fig. 3. Dose-response curve for the influence of dexamethasone on microaggregate formation. Larvae of $Z$. atratus were first injected with the doses of dexamethasone indicated and then intrahemocoelically injected with LPS. At $1 \mathrm{~h}$ PI, microaggregation was assessed. Each point $(n=15)$ indicates the mean number of nodules found in each insect, and the error bars represent one SEM. 20:4n-6 (Fig. 4). In this experiment, ethanol-treated control insects yielded slightly over $1.5 \times 10^{5}$ microaggregates $/ \mathrm{ml}$ hemolymph, while dexamethasone-treated insects yielded about $0.5 \times 10^{5}$ microaggregates $/ \mathrm{ml} \mathrm{hemolymph}$. Another group of larvae were first treated with dexamethasone, then injected with LPS, and then given an injection of 20:4n6 . We recovered nearly $2.5 \times 10^{5}$ microaggregates $/ \mathrm{ml}$ hemolymph from these insects. To control for the possibility that the third injection would somehow stimulate increased microaggregation, a fourth group of larvae was treated with dexamethasone, challenged with LPS, and then injected with the fatty acid vehicle, ethanol. At about $\quad 0.5 \times 10^{5}$ microaggregates $/ \mathrm{ml}$ hemolymph, microaggregation in these insects was similar to that in the dexamethasone-treated counterparts.

We recorded the influence of ibuprofen, a specific cyclooxygenase inhibitor, and of esculetin, a 5- and 12lipoxygenase inhibitor, on microaggregation reactions to LPS challenge (Fig. 5). Compared with controls, insects treated with either of these inhibitors yielded significantly reduced numbers of microaggregates, approximately $0.5 \times 10^{5}$ microaggregates $/ \mathrm{ml}$ hemolymph, on par with the results of dexamethasone treatments.

\section{Discussion}

In this paper we report on two insights into cellular defense reactions in larvae of the tenebrionid beetle, $Z$. atratus. First, the larvae form hemocytic microaggre-

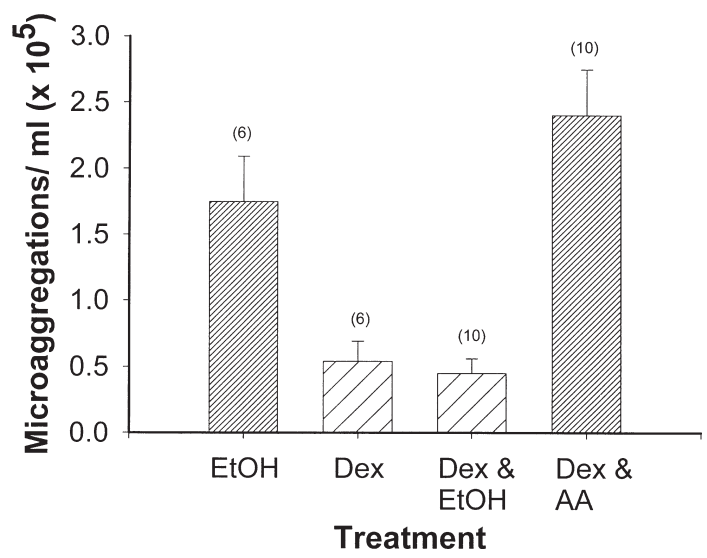

Fig. 4. Arachidonic acid reverses the effect of dexamethasone on microaggregate formation. Insects were treated with ethanol (EtOH) or dexamethasone (Dex) and then injected with LPS. Immediately after injection, test insects were treated with $20 \mu \mathrm{g}$ of arachidonic acid (Dex+AA). Control insects were treated with dexamethasone and ethanol $(\mathrm{Dex}+\mathrm{EtOH})$. At $1 \mathrm{~h}$ PI, microaggregation was assessed. The height of histogram bars represents the mean number of microaggregates found in each insect, and the error bars represent one SEM. Histogram bars with the same fill pattern are not significantly different from each other (LSD, $P<0.01$ ). The numbers in parentheses above the error bars indicate the number of insects in each treatment. 


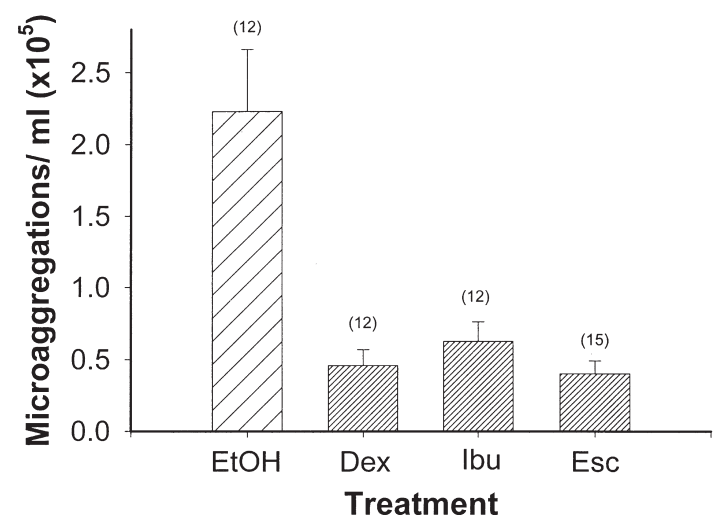

Fig. 5. Effects of treating Z. atratus larvae with individual eicosanoid biosynthesis inhibitors on microaggregate formation in response to intrahemocoelic injections of LPS. Test insects were first injected with $26 \mu \mathrm{g}$ of either dexamethasone (Dex; PLA ${ }_{2}$ inhibitor), esculetin (Esc; lipoxygenase inhibitor) or ibuprofen (Ibu). Control insects were first injected with ethanol (EtOH). Test and control insects were then intrahemocoelically injected with $200 \mu \mathrm{g}$ of LPS. At $1 \mathrm{~h}$ PI, the insects were anesthetized on ice and nodulation was assessed. Each bar indicates the mean number of microaggregates found in each insect, and the error bars represent one SEM. Histogram bars with the same fill pattern are not significantly different from each other (LSD, $P<0.01$ ). The numbers in parentheses above the error bars indicate the number of insects in each treatment.

gates in reaction to LPS challenge and, second, the microaggregate reaction is mediated by eicosanoids. The idea that LPS can stimulate cellular defense reactions is well established in mammalian immunology (Weinstein et al., 1991), as well as in several invertebrate species, including mussels (Tunkijjanukij et al., 1997), annelid worms (Beschin et al., 1998), crustaceans (Lorenzon et al., 1997) and sea urchins (Smith et al., 1995). LPS-binding proteins have been detected in hemolymph from a variety of insect species, such as the silkworm, B. mori (Koizumi et al., 1997), the American cockroach, Periplaneta americana (Jomori et al., 1990), the bloodsucking bug, Triatoma infestans (Hypsa and Grubhoffer, 1995), and the fruitfly, Ceratitis capitata (Charalambidis et al., 1996). We infer that recognition of LPS as a component of certain bacterial cell surfaces is a general mechanism of cellular host defense systems. Less is known, however, about the biochemical events that mediate cellular reactions to LPS.

Several lines of evidence support our view that $Z$. atratus cellular reactions to purified LPS are mediated by eicosanoids. First, dexamethasone treatments severely curtailed LPS-induced microaggregate formation throughout the time course of the experiments. Second, the influence of dexamethasone on LPS-induced microaggregation was expressed in a dose-related manner. Third, the influence of dexamethasone on LPSinduced microaggregation was reversed by injecting arachidonic acid, an eicosanoid-precursor fatty acid, into dexamethasone-treated, LPS-challenged insects. Fourth, independent inhibition of the two major eicosanoid biosynthetic pathways, cyclooxygenase and lipoxygenase, substantially reduced microaggregation reactions to LPS challenge. These points have been discussed in detail elsewhere (Miller et al., 1996; Stanley, 2000), and this information is not repeated here. In the same vein, the pitfalls of relying on pharmaceutical inhibitors of eicosanoid biosynthesis as probes have been treated (Stanley-Samuelson, 1994). As posited for insect cellular reactions to bacterial infections (Stanley and Howard, 1998; Stanley, 2000), these findings strongly support the hypothesis that eicosanoids mediate cellular reactions to LPS challenge.

The significance of this idea lies in understanding the system of signal transduction pathways that operate between the recognition of a bacterial infection and the cellular defense reactions to the infection. As suggested in the Introduction, eicosanoids comprise one element of the system. The work of Downer and colleagues (Baines et al., 1992) shows that biogenic amines make up another element. Certainly there are others, and recent work with LPS is beginning to reveal some of them. Foukas et al. (1998) suggested that the Ras/mitogen-activated protein kinase pathway and integrin receptors are required for cellular internalization of LPS by hemocytes from $C$. capitata. So far, then, eicosanoids, biogenic amines and kinase pathways have been recognized as important elements in mediating cellular defense reactions to bacterial challenge. We anticipate that several other pathways will come to light in the near future. The emerging challenge, then, will be to develop a sophisticated understanding of multiple signal transduction systems in insect immunity.

\section{Acknowledgements}

We thank Drs Leon Higley and Rose Rosario for critically reviewing a draft of this paper. This is paper number 12,942 of the Nebraska Agricultural Research Division. This work was support by the Agricultural Research Division, UNL (Project NEB-17-054), by the USDA-ARS Specific Cooperative Agreement (\#585430-5-115) to D.W.S. and by a grant from the Office of Naval Research (\#N0014-95-1-0553) to R.L.P.

\section{References}

Baines, D., de Santis, T., Downer, R.G.H., 1992. Octopamine and 5hydroxytryptamine enhance the phagocytic and nodule formation activities of cockroach (Periplaneta americana) haemocytes. Journal of Insect Physiology 38, 905-914.

Bell, E.J., Bell, E.T., 1988. Proteins and Enzymes, Chapter 1. Prentice Hall, Inc, Englewood Cliffs, NJ.

Beschin, A., Bilej, M., Hanssens, F., Raymakers, J., Van Dyck, E., Revets, H., Brys, L., Gomez, J., De Baetselier, P., Timmermans, M., 1998. Identification and cloning of a glucan- and lipopolysac- 
charide-binding protein from Eisenia foetida earthworm involved in the activation of prophenoloxidase cascade. Journal of Biological Chemistry 273, 24948-24954.

Charalambidis, N.D., Zervas, C.G., Lambropoulou, M., Katsoris, P.G., Marmaras, V.J., 1995. Lipopolysaccharide-stimulated exocytosis of nonself recognition protein from insect haemocytes depend on protein tyrosine phosphorylation. European Journal of Cell Biology $67,32-41$.

Charalambidis, N.D., Foukas, L.C., Zervas, C.G., Marmaras, V.J., 1996. Hemocyte surface phenolxoidase (PO) and immune response to lipopolysaccharide (LPS) in Ceratitis capitata. Insect Biochemistry and Molecular Biology 26, 867-874.

Foukas, L.C., Katsoulas, H.L., Paraskevopoulou, N., Metheniti, A., Lambropoulou, M., Marmaras, V.J., 1998. Phagocytosis of Escherichia coli by insect hemocytes requires both activation of the Ras/mitogen-activated protein kinase signal transduction pathway for attachment and $\beta_{3}$ for internalization. Journal of Biological Chemistry 273, 14813-14818.

Horohov, D.W., Dunn, P.E., 1983. Phagocytosis and nodule formation by hemocytes of Manduca sexta larvae following injection of Pseudomonas aeruginosa. Journal of Invertebrate Pathology 41, 203-213.

Howard, R.W., Miller, J.S., Stanley, D.W., 1998. The influence of bacterial species and intensity of infections on nodule formation in insects. Journal of Insect Physiology 44, 157-164.

Hypsa, V., Grubhoffer, L., 1995. An LPS-binding hemagglutinin in the midgut of Triatoma infestans: partial characterization and tissue localization. Archives of Insect Biochemistry and Physiology 28, 247-255.

Jomori, T., Kubo, T., Natori, S., 1990. Purification and characterization of lipopolysaccharide-binding protein from hemolymph of American cockroach Periplaneta americana. European Journal of Biochemistry 190, 201-206.

Jurenka, R.A., Miller, J.S., Pedibhotla, V.K., Rana, R.L., StanleySamuelson, D.W., 1997. Eicosanoids mediate microaggregation and nodulation responses to bacterial infections in black cutworms, Agrotis ipsilon, and true armyworms, Pseudaletia unipuncta. Journal of Insect Physiology 43, 125-133.

Kanost, M.R., Dai, W., Dunn, P.E., 1988. Peptidoglycan fragments elicit antibacterial protein synthesis in larvae of Manduca sexta. Archives of Insect Biochemistry and Physiology 8, 147-158.

Koizumi, N., Morozumi, A., Imamura, M., Tanaka, E., Iwahana, H., Sato, R., 1997. Lipopolysaccharide-binding proteins and their involvement in the bacterial clearance from the hemolymph of the silkworm Bombyx mori. European Journal of Biochemistry 248, 217-224.

Lorenzon, S., Giulianini, P.G., Ferrero, E.A., 1997. Lipopolysaccharide-induced hyperglycemia is mediated by $\mathrm{CHH}$ release in crustaceans. General and Comparative Endocrinology 108, 395-405.

Mandato, C.A., Diehl-Jones, W.L., Moore, S.J., Downer, R.G.H., 1997. The effects of eicosanoid biosynthesis inhibitors on prophenoloxidase activation, phagocytosis and cell spreading in Galleria mellonella. Journal of Insect Physiology 43, 1-8.

Miller, J.S., Stanley, D.W., 1998. The nodule formation reaction to bacterial infection: assessing the role of eicosanoids. In: Wiesner, A. et al. (Eds.), Techniques in Insect Immunity. SOS Publications, Fair Haven, NJ, pp. 265-270.

Miller, J.S., Nguyen, T., Stanley-Samuelson, D.W., 1994. Eicosanoids mediate insect nodulation responses to bacterial infections. Proceedings of the National Academy of Sciences, USA 91, 1241812422.

Miller, J.S., Howard, R.W., Nguyen, T., Nguyen, A., Rosario, R.M.T., Stanley-Samuelson, D.W., 1996. Eicosanoids mediate nodulation responses to bacterial infections in larvae of the tenebrionid beetle, Zophobas atratus. Journal of Insect Physiology 42, 3-12.

Miller, J.S., Howard, R.W., Rana, R.L., Tunaz, H., Stanley, D.W., 1999. Eicosanoids mediate nodulation reactions to bacterial infections in adults of the cricket, Gryllus assimilis. Journal of Insect Physiology 45, 75-83.

Morishima, I., Yamano, Y., Knoue, K., Matsuo, N., 1997. Eicosanoids mediate induction of immune genes in the fat body of the silkworm, Bombyx mori. FEBS Letters 419, 83-86.

Smith, L.C., Britten, R.J., Davidson, E.H., 1995. Lipopolysaccharide activates the sea urchin immune system. Developmental and Comparative Immunology 19, 217-224.

Stanley, D.W., 2000. Eicosanoids in Invertebrate Signal Transduction Systems. Princeton University Press, Princeton, NJ.

Stanley, D.W., Howard, R.W., 1998. The biology of prostaglandins and related eicosanoids in invertebrates: cellular, organismal and ecological actions. American Zoologist 38, 369-381.

Stanley-Samuelson, D.W., 1994. Assessing the significance of prostaglandins and other eicosanoids in insect physiology. Journal of Insect Physiology 40, 3-11.

Stanley-Samuelson, D.W., Loher, W., 1986. Prostaglandins in insect reproduction. Annals of the Entomological Society of America 79, 841-853.

Stanley-Samuelson, D.W., Jensen, E., Nickerson, K.W., Tiebel, K., Ogg, C.L., Howard, R.W., 1991. Insect immune response to bacterial infection is mediated by eicosanoids. Proceedings of the National Academy of Sciences, USA 88, 1064-1068.

Stanley-Samuelson, D.W., Pedibhotla, V.K., Rana, R.L., Nor Aliza, A.R., Hoback, W.W., Miller, J.S., 1997. Eicosanoids mediate nodulation responses to bacterial infections in larvae of the silkmoth, Bombyx mori. Comparative Biochemistry and Physiology 118A, 93-100.

Tunaz, H., Bedick, J.C., Miller, J.S., Hoback, W.W., Rana, R.L., Stanley, D.W., 1999. Eicosanoids mediate nodulation reactions to bacterial infections in adults of two 17-year periodical cicadas, Magicicada septendecim and M. cassini. Journal of Insect Physiology 45, 923-931.

Tunkijjanukij, S., Mikkelsen, H.V., Olafsen, J.A., 1997. A heterogeneous sialic acid-binding lectin with affinity for bacterial LPS from horse mussel (Modiolus modiolus) hemolymph. Comparative Biochemistry and Physiology 117B, 273-286.

Weinstein, S., Gold, M.R., DeFranco, A., 1991. Bacterial lipopolysaccharide stimulates protein-tyrosine phosphorylation in macrophages. Proceedings of the National Academy of Sciences, USA 88, 4148-4152. 